\title{
Evaluation of IgG, IgA and IgM against Mycobacterial Antigen in Patients with Extrapulmonary Tuberculosis
}

\author{
Ngangom. Arunkumar Singh ${ }^{1}$, Tina Das $^{2}$, Sungdirenla Jamir ${ }^{3}$ \\ ${ }^{1}$ Assistant Professor, ${ }^{2}$ Senior Resident, ${ }^{3}$ Post Graduate Trainee, \\ Department of Biochemistry, Regional Institute of Medical Sciences, Imphal, Manipur
}

Corresponding Author: Ngangom. Arunkumar Singh

\begin{abstract}
Tuberculosis (TB) is a specific infectious disease usually caused by the tubercle bacillus, Mycobacterium tuberculosis (MBT). It primarily affects the lungs and causes pulmonary tuberculosis (PTB) and when it affects other organs it is known as extrapulmonary tuberculosis (EPTB). The diagnosis of TB largely depends on case history, clinical examination, radiological finding and subsequent laboratory confirmation by bacteriological examination. But the radiological findings are not specific and the sensitivity of AFB (acid fast bacilli) smear is poor. To overcome this difficulty, various serological tests have been tried. A novel antigen namely A60 antigen was found to be highly immunogenic and this present study was carried out to see the diagnostic significance of the ELISA test for A60 antigen in diagnosing extrapulmonary tuberculosis. The study was designed as a cross-sectional study involving both extrapulmonary TB patients and controls. Their serum immunoglobulins ( $\mathrm{IgG}, \operatorname{IgA}$ and $\operatorname{IgM})$ specific toA60 antigen were measured by enzyme linked immunosorbent assay (ELISA) technique. In this study, $\operatorname{IgG}, \operatorname{Ig} \mathrm{A}$ and $\operatorname{IgM}$ was significantly elevated among the EPTB patients as compared to the controls and the IgA and IgM ELISA test combinations was most ideal in diagnosing EPTB.
\end{abstract}

Key words: Tuberculosis, Extrapulmonary tuberculosis, AFB (acid fast bacilli), A60 antigen, ELISA (enzyme linked immunosorbent assay), Immunoglobulin.

\section{INTRODUCTION}

Tuberculosis (TB) is a specific infectious disease usually caused by the tubercle bacillus, Mycobacterium tuberculosis (MBT). It primarily affects the lungs and causes pulmonary tuberculosis (PTB) but when it affects other organs like intestine, bones and joints, lymph gland, skin and other tissues of the body then it is known as extrapulmonary tuberculosis (EPTB).

Extrapulmonary case: a patient with $\mathrm{TB}$ of organs other than lungs (e.g. pleura, lymph nodes, abdomen, genitourinary tract, skin, joints and bones, meninges). Diagnosis should be based on one culture-positive specimen, or histological or strong clinical evidence consistent with active extrapulmonary disease, followed by a decision by a clinician to treat with a full course of antituberculosis chemotherapy. A patient in whom both pulmonary and extrapulmonary have been diagnosed should be classified as pulmonary case.

Early diagnosis and treatment of TB is essential for containment of the disease and hence reducing its morbidity and mortality. So far, the diagnosis of TB largely depends on case history, clinical examination, radiological finding and subsequent laboratory confirmation by bacteriological examination. Smear examination and in vitro culture of tubercle bacillus remain the gold standard. ${ }^{[1]}$ But unfortunately the clinical features of the 
disease are not specific. ${ }^{[2]}$ Moreover the radiological finding is non-specific. The sensitivity of AFB smear is poor. The in vitro culture methods are time consuming and often delay treatment. ${ }^{[1]}$ Newer techniques like DNA hybridization and PCR though more sensitive and specific are not cost effective and require technical skills. Moreover they have restricted availability specially in a developing country. ${ }^{[3]}$

To overcome this difficulty, various serological tests have been tried. A novel antigen namely A60 antigen was prepared from the cytoplasm of Mycobacterium bovis BCG and found to be highly immunogenic. ${ }^{[4]}$ Later it was found that it could be used successfully to detect $\operatorname{IgG}, \operatorname{IgM}$ and $\operatorname{Ig} \mathrm{A}$ class of antibodies using ELISA technique. Antigen A60 is the main thermostable component of old tuberculin (OT) and purified protein derivative (PPD). It belongs to a family of Thermostable Macromolecular antigen (TMA) of microorganisms from the genera Corynebacterium, Mycobacterium and Nocardia (CMN group). The antigenicity of A60 is shared by both Mycobacterium tuberculosis and Mycobacterium bovis. Even a small percentage $(7.8 \%)$ of A60 epitopes proved to be species specific. ${ }^{5}$ The diagnostic significance of ELISA test using this antigen varies in different studies. The present study is carried out to see the significance of the test in diagnosing extrapulmonary tuberculosis (EPTB) among the patients attending RIMS Hospital, Manipur.

\section{Aims and objects}

1) To estimate the serum levels of the immunoglobulins $\operatorname{IgG}$, IgA and $\operatorname{IgM}$ specific to A60 antigen by ELISA technique.

2) To estimate the sensitivity and specificity of the IgG ELISA test, IgA ELISA test and IgM ELISA test by taking a cut-off value.

3) To evaluate the role of A60 based ELISA test for the rapid diagnosis of extrapulmonary tuberculosis.

\section{MATERIALS AND METHODS}

The study was carried out in the Department of Biochemistry, in collaboration with the Department of Tuberculosis and Respiratory Diseases, Regional Institute of Medical Sciences, Imphal during the period from

Study design: Cross sectional study

Study duration: 24 months September, 2014 to August, 2016.

Sample size: 38 extrapulmonary TB (EPTB) patients and 50 healthy controls

\section{Study Population:}

Inclusion criteria: All extrapulmonary TB cases (TB of organs other than lungs, such as the pleura, lymph nodes, genito urinary tract, skeletal, meninges and tuberculoma, gastrointestinal tract, pericardium, etc.) attending the OPD of the Department of Tuberculosis and Respiratory Diseases as well as other departments during the study period were chosen as the study group

Diagnosis of EPTB was made when one of the following conditions was satisfied:

1) One culture positive sample from an extrapulmonary site.

2) Histological evidence of tuberculosis

3) Strong clinical evidence consistent with the active extrapulmonary TB followed by the decision of the examining doctor to treat with a full course of anti-TB therapy.

\section{Exclusion criteria:}

Exclusion criteria for the EPTB patients:

1) Immunocompromised individuals

2) Patients on immunocompromised drugs

3) Patients with known HIV status

4) Patients with signs and symptoms suggestive of AIDS

5) Patients with diseases like diabetes mellitus, hepatic failure, renal failure who may possibly exhibit an altered immune response

6) Patients with earlier history of antitubercular therapy

7) Patients not willing to give consent 
Controls: Another group consisting of apparently healthy individuals who were age and sex matched with the TB patients and free from tuberculosis comprise the control group.

Exclusion criteria for the control group:

1) Any individual with history of fever for more than 3 weeks

2) Any individual with history of cough for more than 3 weeks

3) Individual with history of hemoptysis

4) Individual with complaints of chest pain

5) Patients with any palpable lymphadenopathy

Methods: Informed consent was taken from both the EPTB patients and healthy controls before the start of the study. A detailed clinical history of each case regarding name, age, sex, religion, educational status, marital status, duration of disease, history of smoking and alcohol consumption, family history of TB, history of contact, any history of previous anti-tubercular treatment were recorded. General physical and systemic examinations of both the groups were carried out and in case of EPTB patients the site of the lesions were examined whenever possible.

Sample collection: From both the study groups about $2 \mathrm{ml}$ of venous blood samples were collected from any prominent veins in front of the elbow or forearm. The blood samples thus collected were allowed to clot at room temperature in sterile vials and the serum was then extracted. The serum samples were then kept frozen until further use.

\section{Laboratory tests done:}

The anti-A60 IgG, IgA and IgM were measured by enzyme linked immunosorbent assay technique following the methods as described by Cocito CG, (1991). ${ }^{6}$ Three ELISA tests namely anti A60 IgG-ELISA, anti A60 IgA-ELISA and anti A60 IgM-ELISA tests was done so as to see if there were any significant difference in the serum immunoglobulin levels between the two groups. Further by taking a cut-off value of the serum immunoglobulin level, the validities of the three tests were evaluated in terms of sensitivity and specificity

Ethical clearance: Approval was taken from the Institutional ethical subcommittee RIMS, Imphal.

Statistical analysis: For analysis purpose, the test results of the three ELISA tests were expressed in proportions and compared. For comparison of the mean values ANOVA test was used, while for comparison of proportions, chi square test was used to see the statistical signifance. A p-value of $<0.05$ was considered significant.

\section{RESULTS}

\section{Demographic variables}

Table-1: Sex distribution among the controls and TB patients

\begin{tabular}{|l|l|l|}
\hline Sex & Controls n (\%) & TB patients n (\%) \\
\hline Male & $30(60.0 \%)$ & $26(68 \%)$ \\
\hline Female & $20(40.0 \%)$ & $12(32 \%)$ \\
\hline Total & $50(100.0 \%)$ & $38(100.0 \%)$ \\
\hline
\end{tabular}

It was observed from the above table that the EPTB patients and controls were comparable by sex.

Table-2: Age distribution among the controls and EPTB patients.

\begin{tabular}{|l|l|l|}
\hline $\begin{array}{l}\text { Age } \\
\text { (years) }\end{array}$ & $\begin{array}{l}\text { Controls } \\
\mathbf{n}(\%)\end{array}$ & $\begin{array}{l}\text { EPTB patients } \\
\mathbf{n}(\%)\end{array}$ \\
\hline $15-35$ & $20(40.0 \%)$ & $8(21 \%)$ \\
\hline $36-55$ & $16(32.0 \%)$ & $16(42 \%)$ \\
\hline $56-75$ & $12(24.0 \%)$ & $10(26 \%)$ \\
\hline$>75$ & $2(4.0 \%)$ & $4(11 \%)$ \\
\hline Total & $50(100.0 \%)$ & $38(100.0 \%)$ \\
\hline
\end{tabular}

The above table showed that the EPTB patients and the controls were comparable by age when different age groups were considered. The mean age of controls (43.70yrs) and EPTB patients (43.79yrs) was also comparable.

\section{Evaluation of specific Immunoglobulins:}

Table-3: Mean serum level of IgG antibodies (in EU/ml) among controls and EPTB patients.

\begin{tabular}{|l|l|l|l|l|l|}
\hline Study groups & No. & Mean & S.D. & Range & p-value \\
\hline Controls & 50 & 167.8 & 53.5 & $70-340$ & \\
\cline { 1 - 5 } EPTB patients & 38 & 279.5 & 109.7 & $120-580$ & \multirow{2}{*}{$<0.001$} \\
\hline
\end{tabular}


Ngangom. Arunkumar Singh et.al. Evaluation of $\operatorname{Ig} G, \operatorname{IgA}$ and $\operatorname{Ig} M$ against mycobacterial antigen in patients with extrapulmonary tuberculosis.

The above table showed the comparison of the means of different groups by ANOVA test. It was found that the mean serum levels of $\operatorname{IgG}$ antibodies were significantly elevated among the EPTB patients as compared to the controls.

Table-4: Mean serum level of IgA antibodies (in EU/ml) among controls and EPTB patients.

\begin{tabular}{|l|l|l|l|l|l|}
\hline Study groups & No. & Mean & S.D. & Range & p-value \\
\hline Controls & 50 & 159.0 & 64.9 & $50-370$ & \\
\cline { 1 - 5 } EPTB patients & 38 & 298.9 & 131.8 & $100-800$ & \multirow{2}{*}{$<0.001$} \\
\hline
\end{tabular}

The above table showed that the mean serum IgA levels were significantly elevated in EPTB patients when compared to the controls.

Table-5: Mean optical density (O.D.) of serum IgM level among controls and EPTB patients.

\begin{tabular}{|l|l|l|l|l|l|}
\hline Study groups & No. & Mean & S.D. & Range & p-value \\
\hline
\end{tabular}

\begin{tabular}{|l|l|l|l|l|}
\hline Controls & 50 & 0.282 & 0.122 & $0.123-0.614$ \\
\hline
\end{tabular}

\begin{tabular}{|c|c|c|c|c|}
\hline EPTB & 38 & 0.521 & 0.243 & 0 \\
\hline
\end{tabular}

This table showed that the mean OD's of serum IgM level of the EPTB patients were significantly higher than the controls.

Table-6: IgG positivity among controls and EPTB patients by taking $225 \mathrm{EU} / \mathrm{ml}$ as cut off value.

\begin{tabular}{|l|l|l|l|l|}
\hline \multirow{2}{*}{$\begin{array}{l}\text { Study } \\
\text { groups }\end{array}$} & \multirow{2}{*}{$\begin{array}{l}\text { Total } \\
\text { n(\%) }\end{array}$} & $\begin{array}{l}\text { Test results } \\
\text { IgG +ve } \\
\mathbf{n}(\%)\end{array}$ & $\begin{array}{l}\text { IgG - ve } \\
\mathbf{n}(\%)\end{array}$ & $\begin{array}{l}\text { p- } \\
\text { value }\end{array}$ \\
\hline Controls & $50(100 \%)$ & $6(12.0 \%)$ & $44(88.0 \%)$ & $<0.001$ \\
\hline $\begin{array}{l}\text { EPTB } \\
\text { patients }\end{array}$ & $38(100 \%)$ & $24(63.2 \%)$ & $14(36.8 \%)$ & \\
\hline
\end{tabular}

The above table showed the comparison of IgG ELISA among EPTB patients and controls and it was seen that
IgG ELISA test was significantly positive among the EPTB patients than the controls.

Table -7: IgA positivity among controls and EPTB patients by taking $350 \mathrm{U} / \mathrm{ml}$ as cut off value.

\begin{tabular}{|l|l|l|l|l|}
\hline $\begin{array}{l}\text { Study } \\
\text { groups }\end{array}$ & $\begin{array}{l}\text { Total } \\
\mathbf{n}(\%)\end{array}$ & $\begin{array}{l}\text { Test results } \\
\text { IgA +ve } \\
\mathbf{n}(\%)\end{array}$ & $\begin{array}{l}\text { IgA - ve } \\
\text { n(\%) }\end{array}$ & $\begin{array}{l}\text { p- } \\
\text { value }\end{array}$ \\
\hline Controls & $50(100 \%)$ & $3(6.0 \%)$ & $47(94.0 \%)$ & $<0.001$ \\
\hline $\begin{array}{l}\text { EPTB } \\
\text { patients }\end{array}$ & $38(100 \%)$ & $17(44.7 \%)$ & $21(55.3 \%)$ & \\
\hline
\end{tabular}

It was observed from Table-7 that most EPTB patients were tested negative for IgA ELISA test and a similar finding was seen among the controls.

Table-8: IgM positivity among controls and EPTB patients by taking a value of 1 as cut off value.

\begin{tabular}{|c|c|c|c|c|}
\hline \multirow{2}{*}{$\begin{array}{l}\text { Study } \\
\text { groups }\end{array}$} & \multirow{2}{*}{$\begin{array}{l}\text { Total } \\
\text { n(\%) }\end{array}$} & \multicolumn{2}{|c|}{ Test results } & \multirow[b]{2}{*}{$\begin{array}{l}\text { p- } \\
\text { value }\end{array}$} \\
\hline & & $\begin{array}{l}\text { IgM +ve } \\
\text { n(\%) }\end{array}$ & $\begin{array}{l}\text { IgM - ve } \\
\text { n(\%) }\end{array}$ & \\
\hline Controls & $50(100 \%)$ & $5(10.0 \%)$ & $45(90.0 \%)$ & \multirow[t]{2}{*}{$<0.001$} \\
\hline $\begin{array}{l}\text { EPTB } \\
\text { patients }\end{array}$ & $38(100 \%)$ & $20(52.6 \%)$ & $18(47.4 \%)$ & \\
\hline
\end{tabular}

It was observed from Table- 8 that the EPTB patients were more significantly positive for IgM ELISA test than the controls.

Table-9: Sensitivity of the three ELISA tests among the EPTB patients.

\begin{tabular}{|l|l|l|l|}
\hline \multirow{2}{*}{ Study group } & \multicolumn{3}{|l|}{ Types of ELISA tests } \\
\cline { 2 - 4 } & IgG ELISA & IgA ELISA & IgM ELISA \\
\hline EPTB patients & $63.2 \%$ & $44.7 \%$ & $52.6 \%$ \\
\hline
\end{tabular}

It was observed from Table-9 that of the three ELISA tests, IgG ELISA had the highest sensitivity among the EPTB patients and IgA ELISA had the least sensitivity.

Table-10: Sensitivity of the three ELISA tests in different combinations among the EPTB patients.

\begin{tabular}{|l|l|l|l|l|}
\hline \multirow{2}{*}{ Study group } & \multicolumn{3}{|c|}{ Different combinations of the three ELISA tests } \\
\cline { 2 - 5 } & IgG + IgA ELISA & IgG + IgM ELISA & IgA + IgM ELISA & IgG + IgA + IgM ELISA \\
\hline EPTB patients & $68.4 \%$ & $81.6 \%$ & $73.7 \%$ & $84.2 \%$ \\
\hline
\end{tabular}

It was observed from the above table that the $\operatorname{IgG}+\operatorname{Ig} \mathrm{A}+\operatorname{IgM}$ ELISA test had the highest sensitivity followed by $\operatorname{IgG}+$ $\operatorname{IgM}$ ELISA test, whereas $\operatorname{IgG}+\operatorname{IgA}$ had the lowest sensitivity in diagnosing EPTB.

Table-11: Overall specificity of the three ELISA tests.

\begin{tabular}{|l|l|}
\hline ELISA tests & Specificity \\
\hline IgG ELISA test & $88.0 \%$ \\
\hline IgA ELISA test & $94.0 \%$ \\
\hline IgM ELISA test & $90.0 \%$ \\
\hline
\end{tabular}

The above table showed that IgA ELISA test had the highest specificity while IgG ELISA test had the least specificity.

Table-12: Overall specificity of the three ELISA tests in different combinations.

\begin{tabular}{|l|l|}
\hline Different combinations of the three ELISA tests & Specificity \\
\hline IgG + IgA ELISA test & $81.0 \%$ \\
\hline IgG + IgM ELISA test & $78.0 \%$ \\
\hline IgA + IgM ELISA test & $84.0 \%$ \\
\hline IgG + IgA + IgM ELISA test & $72.0 \%$ \\
\hline
\end{tabular}


It was evident from the above table that $\operatorname{Ig} \mathrm{A}+\operatorname{IgM}$ ELISA tests combination had the highest specificity while the combination of three ELISA tests had the least specificity.

\section{DISCUSSION}

In the present study, out of 38 adult EPTB patients majority were male comprising $(68 \%)$. This indicates that the disease is more common in male than female. This was similar to other findings. It had been stated that prevalence rate of tuberculosis in male and female are almost similar from childhood through young adult life, thereafter male rates become increasingly greater than female rates. ${ }^{[7]}$ Thus the increased prevalence of the disease in the male may be due to gender difference in the immune response against the mycobacterial infection.

Among males, tuberculosis was found to be more common in the 36-55 yrs age group. This study further shows that the disease was found to be quite common in the young adults in both the males and females and than in males the disease further increased with increasing age and peaked at 36-55 yrs of age and then gradually declined with increasing age while in females the disease peaked at 15-35 yrs of age and then gradually declined with increasing age. In a study done in south India it was found that tuberculosis gradually increased from about 10 yrs of age and peaked at about 55 yrs of age in males and at about 40 yrs of age in females. [8]

In this study, the levels of specific immunoglobulins - IgG, $\operatorname{IgA}$ and $\operatorname{IgM}$ were significantly increased among the EPTB patients as compared to the controls. The mean serum $\operatorname{IgG}$ and $\operatorname{IgA}$ levels were 350.0EU/ml and 311.1 EU/ml respectively among the EPTB patients as compared to 167.8 EU/ml and 159.0 EU/ml respectively among the controls. A mean serum level of 167.8 EU/ml for IgG among the control was almost similar to $171.67 \mathrm{EU} / \mathrm{ml}$ as reported by a study done at Taiwan. ${ }^{[9]}$ A study done at New Delhi reported a mean serum level of IgA among the control as $124.04 \mathrm{EU} / \mathrm{ml}$ which is slightly lower. ${ }^{[10]}$

Among the EPTB patients the mean $\mathrm{IgG}$ and $\mathrm{IgA}$ levels were $279.47 \mathrm{EU} / \mathrm{ml}$ and $288.95 \mathrm{EU} / \mathrm{ml}$ respectively while that of IgM was 0.521 OD. Among the EPTB patients the sensitivity of the three ELISA tests - IgG ELISA test, IgA ELISA test and IgM ELISA test were $63.2 \%, 44.7 \%$ and $52.6 \%$ respectively. A slightly lower sensitivity of $59 \%$ for IgG among EPTB was reported by a study done at Riyadh, Saudi Arabia [11] while a much higher sensitivity of $73.8 \%$ was reported by two different studies, one done at New Delhi ${ }^{[10]}$ done at Naples, Italy ${ }^{[12]}$ Other studies reported sensitivity ranging from $32.2 \%$ [3] to $80 \%{ }^{[13]}$ for IgG among EPTB patients. A higher sensitivity of $69 \%{ }^{[14]}$ was reported in one study for IgA while a lower sensitivity Of $22.3 \%{ }^{[10]}$ was reported for IgM among EPTB patients.

The overall sensitivity of the $\operatorname{IgG}$ ELISA test, IgA ELISA test and IgM ELISA test among the EPTB patients were found to be $63.2 \%, 44.7 \%$ and $52.6 \%$ respectively. The overall specificity of the IgG ELISA test, IgA ELISA test and IgM ELISA tests were found to be $88 \%, 94 \%$ and $90 \%$ respectively in this study. A more or less similar specificity of $88.4 \%$ for $\mathrm{IgG}$, [9] $93.6 \%$ for $\operatorname{IgA}{ }^{[14]}$ and a slightly lower specificity of $87.5 \%$ for $\operatorname{IgM}{ }^{[15]}$ were reported by different studies. The difference in the sensitivity and specificity of the tests from some of the studies may be due to the difference in the prevalence and can ascribe to an increased circulating antibody due to sub-clinical infection which can invariably influence the ELISA tests. Moreover different studies use different cut-off values and this can also influence the test results.

For the definitive diagnosis of EPTB, detection of acid fast bacilli on samples from affected tissue is essential but the sensitivity is poor. The sensitivity for the detection of AFB by culture for the diagnosis of EPTB was reported to be between $27 \%$ - $39 \%$ for the different sites 
involved. [16] Though the characteristic histological feature is helpful in the diagnosis of EPTB, the procedures are invasive. Moreover the M. Tuberculosis growth time is long and usually by the time granuloma is detected by histopathology the disease already is in advanced stage. ${ }^{[12]}$ Some authors reported the detection rate of caseous necrosis in EPTB to as low as $31 \%$. ${ }^{[16]}$ Thus particularly in EPTB when other diagnostic measures have failed to diagnose, the role of a rapid test like that of an ELISA test is important. In this study the $\operatorname{IgG}$ ELISA test had a modest sensitivity for the diagnosis of EPTB while the sensitivity of other ELISA tests are poor. So, in this view several possible combinations of the three ELISA tests were tried with the aim of improving the sensitivity of the test.

When different combinations of the three ELISA tests were tried, their sensitivity were much improved but it was at the cost of their specificity. The main purpose of these combinations was to see which combination had the most ideal sensitivity without much compromise of the specificity. The IgG + IgA, IgG + IgM, IgG $+\operatorname{Ig} \mathrm{A}+\operatorname{IgM}, \operatorname{Ig} \mathrm{A}+\operatorname{IgM}$ ELISA tests combinations had a specificity among the EPTB patients of $68.4 \%, 81.6 \%, 73.7 \%$ and $84.2 \%$ respectively.

The $\operatorname{IgA}$ and $\operatorname{IgM}$ ELISA tests combinations turns out to be the most ideal test combination in the diagnosis of EPTB with a sensitivity and specificity of $73.7 \%$ and $84 \%$.

\section{CONCLUSION}

In this study, $\operatorname{IgG}, \operatorname{Ig} \mathrm{A}$ and $\operatorname{IgM}$ were significantly elevated among the EPTB patients as compared to the controls. Among the 38 EPTB patients the mean serum levels of $\operatorname{IgG}, \operatorname{IgA}$ and $\operatorname{IgM}$ were $279.5 \mathrm{EU} / \mathrm{ml}, 289.9 \mathrm{EU} / \mathrm{ml}$ and $0.521 \mathrm{OD}$ respectively. When different test combinations were tried with the aim of improving the sensitivity of the test, the $\operatorname{Ig} \mathrm{A}$ and IgM ELISA test combinations was most ideal with much improved sensitivity of
$73.7 \%$ and without much compromise in the specificity (84\%).

\section{REFERENCES}

1. Bhatia AS, Kumar Sand Harinath BC. Immunodiagnosis of tuberculosis: An update. Indian Journal of Biochemistry. 2003; 18:1-5.

2. Charpin D, Herbault H, Gevaudan $\mathrm{J}$ et al. Value of ELISA using A60 antigen in the diagnosis of pulmonary tuberculosis. Am. Rev. Of Respir. Dis. 1990; 142:380-84.

3. Caminero JA, Rodriguez de Castro F, Carrillo $\mathrm{T}$ et al. Value of ELISA using A60 antigen in the serodiagnosis of tuberculosis. Respiration. 1994; 61:283-6.

4. Cocito C, Vanlinden F. Preparation and property of antigen 60 from Mycobacterium bovis BCG. Clin. Exp. Immunol. 1986; 66:262-72.

5. Coetsier C, Baelden MC, Coene $\mathrm{M}$ et al. Immunological analysis of the components of the antigen complex A60 of Mycobacterium bovis BCG. Clin. Diagn. Lab. Immunol. 1994; 1:139-44.

6. Cocito CG. Properties of mycobacterial antigen complex A60 and its application to the diagnosis and prognosis of tuberculosis. Chest. 1991; 100: 1687-93.

7. Seaton A, Seaton D, Leitch AG. Crofton and Douglas's respiratory disease. $5^{\text {th }}$ ed. London: Blackwell Science; 2002. p.476506.

8. NTI. Bangalore: Tuberculosis in a rural population of South India - a five year epidemiological study. Bull WHO. 1974; 51:473-8.

9. Chiang IH, Suo J, Bai KJ et al. Serodiagnosis of Tuberculosis : a study comparing three specific mycobacterial antigens. Am. J. Respir. Crit. Care Med. 1997; 156:906-11.

10. Gupta S, Kumari S, Banwalikar JN et al. Diagnostic utility of mycobacterial antigen A60 specific immunoglobulins IgM, IgA and $\operatorname{IgG}$ in the sera of cases of adult human tuberculosis. Tubercle Lung Dis. 1995; 76:418-24.

11. Quadir SMH, Smith KK. Nonspecificity of anda A60-tb ELISA test for serodiagnosis of mycobacterial disease. Can. J. Microbiol. 1992; 38:804-6.

12. Alifano M, Pascalis RD, Sofia $M$ et al. Detection of $\operatorname{IgG}$ and $\operatorname{IgA}$ against the 
Ngangom. Arunkumar Singh et.al. Evaluation of IgG, IgA and IgM against mycobacterial antigen in patients with extrapulmonary tuberculosis.

mycobacterial antigen A60 in patients with extrapulmonary tuberculosis. Thorax. 1998; 53: $377-80$.

13. Munshi MM, Chiddarwar S, Patel A et al. Serodiagnosis of extrapulmonary tuberculosis by ELISA. Indian J. Pathol. Microbiol. 1993; 36:356-60.

14. Alifano M, Sofia M, Mormile M et al. IgA immune response against the mycobacterial antigen A60 antigen in patients with active pulmonary tuberculosis. Respiration. 1996; 63:292-7.

15. Mahajan M, Singh NP, Gadre DJ et al. Detection of IgM antibodies in pulmonary tuberculosis by ELISA using A60 antigen. J. Commun. Dis. 1996; 28:176-80.

16. Weir MR, Thornton GF. Extrapulmonary tuberculosis - experience of a community hospital and review of the literature. Am J Med. 1985; 79:467-78.

How to cite this article: Singh NA, Das T, Jamir S. Evaluation of $\operatorname{IgG}$, IgA and IgM against mycobacterial antigen in patients with extrapulmonary tuberculosis. Gal Int $J$ Health Sci Res. 2021; 6(1): 6-12. 